\title{
EFFECT OF UTILIZATION OF SOCIAL MEDIA PLATFORMS ON YOUTH PARTICIPATION IN AGRICULTURE IN NJORO SUB-COUNTY, KENYA
}

Khumoetsile O. Sebotsa*, Agnes Nkurumwa, Miriam Kyule

Department of Agricultural Education and Extension, Egerton University, Kenya.

ARTICLE INF O

\section{Article history}

Received: August 22, 2020

Revised: December 13, 2020

Accepted: December 28, 2020

\section{Keywords}

Social Media

Youth

Effect

Agriculture

Participation
A B S T R A C T

Most of rural people, particularly in Sub-Saharan Africa, depend on agriculture for their livelihoods. In Kenya, rural households who are mainly smallholder farmers rely on agriculture for most of their income. The agriculture sector plays an important role in employment creation. However, the sector is reportedly dominated by the elderly people while youths tend to shy away. These youths are actively involved on social media platforms hence social media have been used to promote their participation in agriculture. However, how utilization of such social media platforms affected their participation in agriculture was not yet known in Njoro Subcounty. This study focused on the effect of utilization of social media platforms on youth participation in agriculture in Njoro Sub-county. A descriptive survey research design was used with a target population of 3,925 and accessible population of 1,597 youth involved in agriculture in Njoro, Kihingo, and Lare wards. A random sampling technique was used to select 150 respondents. A questionnaire was used to collect data. SPSS version 22 and STATA version 12 was used to analyze data. The results revealed Facebook, Google search engine, and WhatsApp as the top three highly used social media platforms amongst the youth in agriculture in Njoro Sub-county. Besides, Facebook had highest $22 \%$ respondents using it very often, 18\% often, $14.7 \%$ sometimes and $6.7 \%$ rarely. Moreover, the results showed that the level of utilization of social media platforms had a significant effect $(p=0.001)$ on youth participation in agriculture at a $5 \%$ level. WhatsApp had a positive effect $(\mathrm{p}=0.039)$ on youth participation in agriculture at a $5 \%$ level. The study recommended that government and other potential stakeholders should invest in digital extension services to promote youth participation in agriculture. More youth participation would significantly reduce unemployment.

Corresponding Author: Khumoetsile O. Sebotsa

Email: ctvsebotsa@gmail.com

(C) The Author(s) 2020.

\section{INTRODUCTION}

Agriculture is an important sector in the economy of most developing countries in the world. In Sub-Saharan Africa, it accounts for $25 \%-40 \%$ of total Gross Domestic Product (GDP)(Kimaro and Towo, 2015). The agricultural sector plays an important role in employment creation and improving the living standards of people (Ministry of Agriculture Livestock and Fisheries, 2017). In Kenya, rural households who are mainly smallholder farmers, rely on agriculture for most of their income (Olwande and Mathenge, 2011). Agriculture in Kenya has great potential that had not been fully utilized to provide employment to the youth to enable them to exploit their creativity and 
innovativeness (Njeru and Mwangi, 2015). According to the United Nations (UN), youths are people between the age of 15 and 24 years and they represented approximately $16 \%$ of the global population, nearly 1.2 billion people in 2019 of which Africa is considered to be the third continent with the highest number of youthful population of approximately 211 million after central and Southern Asia with 361 million youth and Eastern and South Eastern Asia with 307 million youths (United Nations, 2019) The population demographics of the East African Community (EAC) countries, particularly those of Kenya, Rwanda, Tanzania, and Uganda depict that there are around 127 million people in the four countries. Around $20 \%$ of the population is between the ages of 15 and 24 years and can be labeled as "youth" according to the United Nations' definition (Varner, 2018). In Kenya, youth are defined as people in the age bracket of 18-35 years that account for about $35.4 \%$ of Kenya's population. This youthful population represents a potential group that can increase agricultural production, food security, labor force, and individual as well as the country's income.

According to (Kenya National Bureau of Statistics, 2019b), Nakuru County has an estimated $33 \%$ of the population aged between 18 and 35 years. This large number of youths in the County is faced with a high unemployment rate. The County government through its development plans encourages the youth to engage in income-generating agricultural activities. The integration of youth in agricultural activities is important for the development of the agricultural sector. However, the engagement of the youth in agricultural activities has not been up to the expectations particularly in Kenya where the youths have been encouraged to take up agricultural activities to curb the high unemployment rate (Njeru, Gichimu, et al., 2015). There is evidence revealing that there is a concentration of older farmers in Sub-Saharan Africa, with $27 \%$ of farmers being over the age of 55 years (Heide-Ottosen, 2014). This has been of great concern to the development of the agricultural sector across the region. Therefore, social media has been used as a tool to attract the youth in agriculture since those youth are attracted to technology. A study done by Cline (2011), indicated that the majority of youthful farmers own modern phones and spend most of their time on the internet reading about the animals they keep or the crops they grow, following market and farming trends. Poushter et al. (2018) also indicated that young people are using the internet more than the older generations in SubSaharan Africa. In Kenya, farmers have access to social media platforms such as Mkulima Young, Digital Farmers Kenya, and Mkulima Hub Kenya to obtain agricultural information (Kipkurgat et al., 2016). In Nakuru County, farmers have access to Facebook, Twitter, and WhatsApp social media platforms through the Nakuru Farmers Call Centre (Wahiu et al., 2020). The platforms are widely used by the call center to communicate with the farming community. Social media platforms allow farmers to create and exchange information with their fellow farmers (Akashraj and Pushpa, 2014). Examples of social media platforms include Facebook, LinkedIn, Twitter, Instagram, WhatsApp, and YouTube. Evidence by Starasts (2015) revealed that social media has been used as one of the most widely recognized sources of information useful to the farmer. Lathiya et al. (2015) stated that social media is now the mainstream of communication in the world and it continues to grow as smartphones become more popular. According to Kuria (2014) Social media platforms educate and inform farmers on agricultural issues as well as facilitating the buying and selling of agricultural produce. According to Balkrishna and Deshmukh (2017), social media is a very useful tool in marketing as it saves time and cost of obtaining agricultural information. Young farmers believe more in the use of social media in agricultural marketing. Farmers can engage with one another to seek help and able to solve their agricultural problems such as pest control, access to input and disease control through these platforms with various stakeholders in the sector. Social media has provided farmers with a quick and easy way to build relationships and interact with their customers and fellow farmers in agriculture (Varner, 2018). However, it was not clear how the level of utilization of social media affected participation in agriculture amongst the youth in Njoro Sub-county. This study, therefore, sought to determine the effect of the level of utilization of social media platforms on youth participation in agriculture in Njoro Sub-county.

\section{Objectives of the Study}

The objectives of the study were to;

i. Identify types of social media platforms used in obtaining agricultural information amongst the youth in Njoro Sub-county. 
ii. Determine the extent of utilizing social media platforms to obtain agricultural information amongst the youth in Njoro Sub-county

iii. Determine the effect of utilization of social media platforms on youth participation in agriculture in Njoro Sub-county.

\section{METHODOLOGY}

A descriptive survey research design was used in the study. The study was carried out in Nakuru county specifically Njoro sub-county. Njoro Sub-county stands at an altitude of $1,800 \mathrm{~m}$ above sea level and is situated between 35 28' - 35을 36' E longitude and 0o 13' - 1 10' S latitude (Wambu, 2017). The rainfall in Njoro Subcounty ranges between $700 \mathrm{~mm}$ and $1000 \mathrm{~mm}$ in the lowlands and highlands respectively, with long rains experienced between March and June whereas short rains are experienced between October and December (Wangui et al., 2018). The Sub-county has 6 wards namely; Njoro, Lare, Kihingo, Mau Narok, Nesuit and Mauche and covers an area of approximately $713.3 \mathrm{Km}^{2}$ with a total population of 208,359 (CGoN, 2017). Agriculture is the main economic activity taking place in the Sub-county with agricultural land covering 34,851 hectares (Kenya National Bureau of Statistics, 2019a). There are several agricultural activities taking place in According to Kotrlik and Higgins (2001), the 0.08 allowable error is used to account for both the qualitative and quantitative error acceptable, which is 0.03 for quantitative and 0.05 for qualitative data to be obtained. The allowable errors added together summed to 0.08 and accounted for both continuous and categorical data that were collected in the study. The accessible population was 1,597 youth involved in agriculture from Njoro, Lare and Kihingo wards whereas the sample size required was 150 . Therefore, to determine the number of respondents required from each ward to obtain a sample size of 150 as presented in Table 1, the proportional sampling formula by Salkind (2010) was used as follows; for a finite population with the Sub-county, which include vegetable production, milk processing, large-scale wheat, maize, beans and barley farming at subsistence and commercial level.

Nakuru County was purposively selected out of the 47 Counties in Kenya because it is the only County that has embraced the use of social media in agriculture through the establishment of the Nakuru Farmers Call Centre supported by the County Government. Njoro Sub-county was then purposively selected from Nakuru County out of 11 Sub-counties because it has a large number of the youth participating in agriculture. Njoro, Lare and Kihingo were then, randomly selected out of six wards from Njoro Sub-county. The study targeted 3,925 youths who participated in agriculture in Njoro Sub-county. To determine the sample size, the formula by Yamane (1967) was used as follows;

$n=\frac{N}{1+N\left(e^{2}\right)}$.

Where;

$\mathrm{n}=$ the sample size

$\mathrm{N}=$ Population Size $(3,925)$

$\mathrm{e}=$ Allowable error $(0.08)$

$n=\frac{3925}{1+3925\left(0.08^{2}\right)}=150$

population size $\mathrm{N}$, the population is divided into $\mathrm{H}$ strata which are sub-populations. The size of the $\mathrm{h}^{\text {th }}$ stratum is denoted as Nh and $\sum_{h=1}^{H} N_{h}=N$. Proportional sampling design with total sample size $\mathrm{n}$ was such that;

$n_{h}=n \frac{N_{h}}{N}$

And

$\sum_{h=1}^{H} n_{h}=n$

Where;

$n_{h}=$ Sample size required from each ward

$n=$ Sample size (150)

$N_{h}=$ Ward Population size

$N=$ Total Wards Population $(1,597)$

Table 1. Distribution of Sample Size.

\begin{tabular}{lcc}
\hline Ward & Population & Sample Size \\
\hline Njoro & 692 & 65 \\
Lare & 588 & 55 \\
Kihingo & 319 & 30 \\
\hline Total & 1,597 & 150 \\
\hline
\end{tabular}


A researcher-constructed questionnaire was used to collect data from the 150 sampled youth. The researcher gave the instrument to experts in the field of agricultural extension to ensure validity by checking all the items and ensured they are measuring all the variables under observation. The experts also face validated the instrument by checking that the appearance was appealing to the respondents and did not contain any unnecessary graphics and items that were not part of the study.

Pilot testing was carried out at Molo Sub-county to test for reliability of the instrument. The Cronbach alpha coefficient obtained after testing for reliability was 0.75 which was above the required threshold of 0.70 hence the instrument was found to be reliable. The data collected was organized and cleaned before being analyzed using SPPS version 22 and STATA version 12 . STATA was used to run the ordered logistic regression model because it gave efficient results for interpretation of the model as compared to SPSS. The data were presented using percentages, frequencies, and mean squares.

The hypothesis was tested to determine the effect of the level of utilization of social media platforms on youth participation in agriculture in Njoro Sub-county. The null hypothesis that: 'There is no statistically significant effect of the level of utilization of social media platforms on youth participation in agriculture in Njoro Subcounty', was tested using a linear regression model. The equation of the model was presented as follows,

$y_{i}^{*}=\alpha+\beta x_{i}+\varepsilon_{i}$

Where,

yi*: Dependent variable

$\alpha$ : Constant

$\beta$ : Regression coefficients or change in yi* induced by $x$

$x$ : Independent variable

$\varepsilon$ : Error estimates

The model was used to determine the effect of the explanatory variable which is the level of utilization of social media platforms on youth participation in agriculture which is the outcome variable. However, since the level of utilization varied across platforms, an index score was computed to create the variable level of utilization which gave the combined effect of the platforms on youth participation in agriculture measured in terms of the number of agriculture activities the respondents undertook.

To determine the effect of individual social media platforms in agriculture, an ordered logistic regression model was used. The dependent variable youth participation was ordered. The order was created in line with the number of agricultural activities the respondents undertook with those who undertook 1 to 5 agricultural activities being low youth participation, those who undertook between 6 and 10 agricultural activities being medium youth participation, and those who undertook more than 10 agricultural activities as high youth participation in agriculture. The model equation was presented as follows;

$y_{i}^{*}=\beta^{\prime} x_{i}+\varepsilon_{i} ; \mathrm{i}=1, \ldots, \mathrm{n}-\infty<y_{i}^{*}<\infty$

Where

$y_{i}^{*}$ : Youth Participation

$\beta^{\prime}$ : Vector of the parameter that should be estimated

$x_{i}$ : Observed vector of non-random independent variable which shows the characteristic of the ith person

$\varepsilon_{i}$ : Residual error of the model which is logistically distributed

Since $y_{i}^{*}$ is a latent variable, standard regression techniques are not applicable to estimate the sample size. If $y_{i}$ is observable variable Youth Participation which shows different levels as low, medium and high. The relation between the latent variable $y_{i}^{*}$ and observable variable $y_{i}$ is obtained from the ordered logit model as follows:

$y_{i}=1 \quad$ if $\quad-\infty \leq y_{i}^{*}<\mu_{1}, \quad \mathrm{i}=1, \ldots, \mathrm{n}$,

$y_{i}=2 \quad$ if $\quad \mu_{1} \leq y_{i}^{*}<\mu_{2}, \quad \mathrm{i}=1, \ldots, \mathrm{n}$,

$y_{i}=3 \quad$ if $\quad \mu_{2} \leq y_{i}^{*}<\mu_{3}, \quad \mathrm{i}=1, \ldots, \mathrm{n}$,

$y_{i}=\mathrm{j} \quad$ if $\quad \mu_{j-1} \leq y_{i}^{*}<+\infty, \quad \mathrm{i}=1, \ldots ., \mathrm{n}, \ldots \ldots \ldots .(5)$

In which $\mathrm{n}$ is the sample size.

' $\mu$ ' is the threshold that defines observed discrete answers and should be estimated.

The probability of the $y_{i}=\mathrm{j} \quad$ has been calculated by the following relation

$\operatorname{Pr}\left(y_{1=j}\right)=\operatorname{Pr}\left(y_{1} \geq \mu_{j-1}\right)=\operatorname{Pr}\left(\varepsilon_{1} \geq \mu_{n-1}-\beta x_{1}\right)$

$F\left(\beta x_{1}-\mu_{j-1}\right)$

The hypothesis was then tested for all the individual platforms as the level of utilization varies. The various social media platforms were treated individually as independent variables.

\section{RESULTS AND DISCUSSION}

This section presents the results and discussion of the findings on demographic characteristics of the respondents, the types of social media platforms used in obtaining agricultural information and the type of 
agricultural information obtained through the use of social media platforms. The findings on the extent of utilizing social media platforms to obtain agricultural information and the effect of utilization of social media platforms on youth participation in agriculture in Njoro Sub-county are also presented in this section.

\section{Demographics characteristics of the respondents}

The respondent's demographic characteristics were described in terms of gender, age, and education level and employment status. Table 2 shows that out of the 150 respondents, females accounted for $32 \%$ of the total sample while the male respondents accounted for
$68 \%$ of the total sample. Likewise, the results indicated that out of the 150 respondents, $64 \%$ were 18 to 25 years of age while $17.3 \%$ were 26 to 30 years of age and lastly, those who are 31 years and above made up 18.7 $\%$ of the total sample.

Table 2 results further revealed that $14.0 \%$ have a primary school education, $43.3 \%$ have Secondary (form 4), $8.7 \%$ have certificate level and $14.0 \%$ have a diploma level whereas $19.3 \%$ and $0.7 \%$ have bachelors and master's degrees respectively. Moreover, the results revealed that $44.7 \%$ of the respondents are unemployed whereas $48.7 \%$ are self-employed and $6.6 \%$ of the respondents are employed.

Table 2. Demographics characteristics of the respondents $(n=150)$.

\begin{tabular}{lcc}
\hline \multicolumn{1}{l}{ Variables } & \multicolumn{1}{l}{ Gender } & \\
\hline \multicolumn{1}{l}{ Male } & & 68.0 \\
Female & Age (Years) & 32.0 \\
\hline & & 64.0 \\
\hline 18 to 25 & & 17.3 \\
26 to 30 & Education Level & 18.7 \\
31 and above & & 14.0 \\
\hline & & 43.3 \\
\hline Primary & & 8.7 \\
Secondary (Form 4) & 14.0 \\
Certificate & & 19.3 \\
Diploma & & 0.7 \\
Bachelors & & 44.7 \\
Masters & Employment Status & 48.7 \\
\hline & & 6.7 \\
\hline Unemployed & & \\
Self Employed & & \\
Employed & & \\
\hline
\end{tabular}

\section{Agricultural activities the respondents undertook}

Youth participate in agriculture by engagement in different agricultural activities along the agricultural value chain. The agricultural activities include field crop production, beef production, poultry production, vegetable production, operating a processing plant amongst others. The results in Table 3 revealed the highest agricultural activities the youth engaged in are selling their produce (85.3\%), field crop production (76 $\%)$, poultry farming (74.7\%), and vegetable (68.7\%). The least agricultural activities that the youth participate in are processing agricultural produce and buying agricultural produce for sale accounting for $9.3 \%$ and $25.3 \%$ of the total population respectively. The results imply that the respondents are mostly involved in crop production for sale.

The respondents mainly focused on maize, wheat, tomatoes, kales, cabbages, green peppers, spinach, carrots and onions. Youth participation was then measured in terms of the number of agricultural activities the respondents undertook which were ordered. The data described in the Table 4 shows the number of agricultural activities the respondents undertook. 
Table 3. Agricultural activities of respondents ( $\mathrm{n}=150)$.

\begin{tabular}{lc}
\hline Agricultural Activity & Percentage (\%) of farmers \\
\hline Buying for sale (broker) & 25.3 \\
Selling own produce & 85.3 \\
Linking up with other farmers & 82.0 \\
Providing paid labor in a farm & 54.7 \\
Poultry farming & 74.7 \\
Cattle farming & 28.0 \\
Small stock production & 30.0 \\
Vegetable production & 68.7 \\
Field crop production & 76.0 \\
Sorting for packaging & 59.3 \\
Grading & 45.3 \\
Processing produce & 9.3 \\
\hline Others & 12.0 \\
\hline
\end{tabular}

Table 4. Number of agricultural activities the Respondents undertook $(n=150)$.

\begin{tabular}{lc}
\hline Number of Respondents & Number of Agricultural activities \\
\hline 4 & 1 \\
7 & 2 \\
7 & 3 \\
6 & 4 \\
10 & 5 \\
13 & 6 \\
12 & 7 \\
17 & 8 \\
27 & 9 \\
23 & 10 \\
13 & 11 \\
6 & 12 \\
3 & 13 \\
1 & 14 \\
1 & 16 \\
\hline
\end{tabular}

Use of Social Media Platforms in Agriculture by respondents in Njoro Sub-county

The results in Figure 1 indicate that out of 150 respondents, only $67 \%$ of the respondents used social media for agricultural purposes while $33 \%$ of respondents did not use social media for agricultural purposes. This implies that the majority of the respondents have access to social media platforms for agricultural purposes. However, some respondents indicated that they do not use social media in agriculture. The respondents indicated costly internet data (34\%), Poor network connection (32\%), unavailability of relevant information (18\%), unreliable information on social media (14\%) and less trust concerning E-selling and E-buying (16\%). The majority of the respondents further indicated that they did not understand how social media is used in agriculture while $26 \%$ of the respondents indicated that they did not have a smartphone and $12 \%$ were not aware of the use of social media in agriculture. Table 5 presents the results on the reasons why some of the respondents did not use social media in agriculture. 


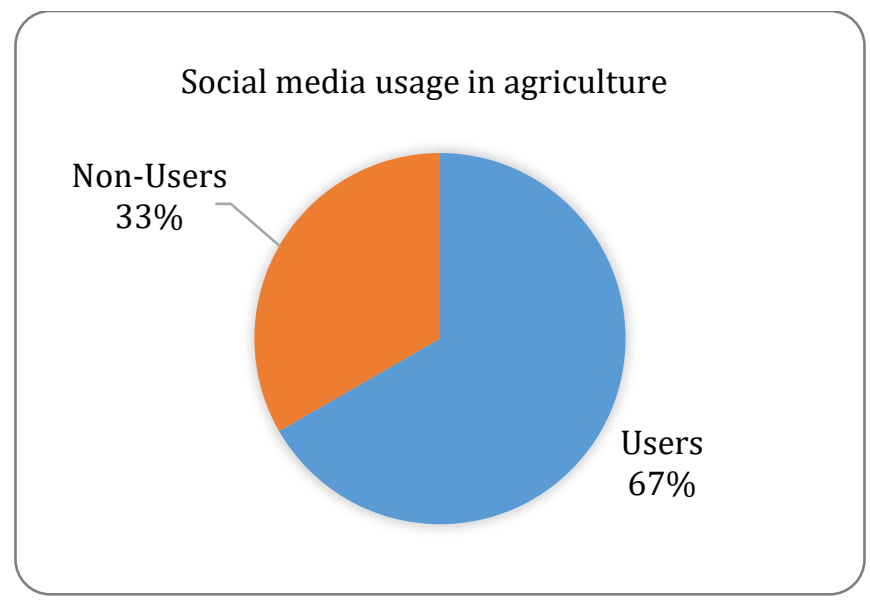

Figure 1. Respondent's use of social media in agriculture.
Type of Social Media Used in Agriculture in Njoro Sub-county

There are various types of social media platforms available for obtaining agricultural information. The respondents indicated that they used WhatsApp, Facebook, Twitter, Instagram, Google search engine, YouTube, Wikipedia, LinkedIn, Mkulima Young, MShamba, and DigiCow to obtain agricultural information. The results revealed that Facebook, Google search engine, and WhatsApp as the top three highly used social media platforms in agriculture with $47.3 \%, 46 \%$, and $41.3 \%$ of usage respectively amongst the youth in agriculture. The results of the type of social media platforms that the respondents are using in agriculture are presented in Table 6.

Table 5. Reasons for not using social media in agriculture $(n=50)$.

\begin{tabular}{lc}
\hline Reason & Percentage (\%) of farmers \\
\hline Costly internet data & 34 \\
Poor network connection & 32 \\
Relevant information not available & 18 \\
Unreliable information on social media & 14 \\
Less trust concerning E-buying & 16 \\
Less trust concerning E-selling & 16 \\
Not aware of the use of social media in agriculture & 12 \\
Do not have a smartphone & 26 \\
Do not understand how social media is used in agriculture & 66 \\
\hline
\end{tabular}

Table 6. Social media platforms used by respondents in agriculture $(n=100)$.

\begin{tabular}{lc}
\hline Type of social media platform & Percentage (\%) of farmers \\
\hline WhatsApp & 41.3 \\
Facebook & 47.3 \\
Twitter & 7.3 \\
Google search engine & 46.0 \\
YouTube & 31.3 \\
Instagram & 6.0 \\
LinkedIn & 1.3 \\
Wikipedia & 8.0 \\
Mkulima Young & 13.3 \\
M-Shamba & 13.3 \\
DigiCow & 4.0 \\
\hline
\end{tabular}

Type Agricultural Information Obtained on Social Media Platforms

The respondents were found to obtain information on the availability of market, animal and crop husbandry practices, agricultural inputs, value addition, and financial institutions. Table 7 indicates that $81 \%$ of the respondents obtain information on crop husbandry practices as the highest, whereas $44 \%$ of respondents obtain information on markets and, only $8 \%$ of the respondents obtaineded information about financial services on social media platforms.

Level of utilization of Social Media Platforms in Agriculture

The study found that respondents used various social media platforms to obtain agricultural information. 
However, the level of utilization of these social media platforms varies across platforms and users. Some respondents did not use social media at all, some rarely; others sometimes while some use it often and others very often. The results indicate that Facebook has the highest number of respondents who use it very often which is $22 \%$ of the total sample followed by WhatsApp and Google search engine both with $18.7 \%$ of the users using the platforms very often. The least platforms used very often are Twitter and LinkedIn with $1.3 \%$ and 0.0 $\%$ of the users respectively using them very often. The majority of the respondents indicated that they do not use Instagram, LinkedIn, Wikipedia, Mkulima Young, MShamba and DigiCow at all in Agriculture with 91.3\%, $96.7 \%, 91.3 \%, 93.3 \%, 91.1 \%$ and $98.0 \%$ respectively. The results on the level of utilization of social media platforms in agriculture by the respondents are presented in Table 8.

Table 7. Type of agricultural information obtained from social media platforms $(n=100)$

\begin{tabular}{lc}
\hline Type of Information & Percentage (\%) of farmers \\
\hline Agricultural inputs & 42 \\
Crop husbandry practices & 81 \\
Livestock husbandry practices & 41 \\
Market information & 44 \\
Value addition & 12 \\
Financial services & 8.0 \\
\hline
\end{tabular}

Table 8. Level of utilization of social media platforms in agriculture.

\begin{tabular}{lccccc}
\hline Variables & Not at All & Rarely & Sometimes & Often & Very Often \\
\cline { 2 - 5 } & \% farmers & \% farmers & \% farmers & \% farmers & \% farmers \\
\hline WhatsApp & 46.7 & 6.0 & 12.7 & 16.0 & 18.7 \\
Facebook & 38.7 & 6.7 & 14.7 & 18.0 & 22.0 \\
Twitter & 85.3 & 5.3 & 6.7 & 1.3 & 1.3 \\
Google Search Engine & 41.3 & 9.3 & 16.0 & 14.7 & 18.7 \\
YouTube & 57.3 & 7.3 & 10.7 & 16.0 & 8.7 \\
Instagram & 91.3 & 4.0 & 2.0 & 2.0 & 0.7 \\
LinkedIn & 96.7 & 0.0 & 2.7 & 0.7 & 0.0 \\
Wikipedia & 91.3 & 2.0 & 3.3 & 0.7 & 2.7 \\
Mkulima Young & 93.3 & 1.3 & 2.0 & 1.3 & 2.0 \\
M-Shamba & 91.3 & 2.0 & 1.3 & 2.0 & 3.3 \\
DigiCow & 98.0 & 0.7 & 0.7 & 0.7 & 0.7 \\
\hline
\end{tabular}

Table 6 indicates that the level of utilization was significant $(p=0.001)$. The F-ratio $(1,148)$ was equal to 11.941 with a statistically significant $p$-value of 0.001 at a 5\% level as presented in Table 9. Therefore, we reject the null hypothesis and accept the alternative hypothesis and conclude that there is a statistically significant effect on the level of utilization of social media platforms on youth participation in agriculture.

Table 9. Effect of Level of the utilization of social media platforms on youth participation in agriculture.

\begin{tabular}{lcccc}
\hline Variable & Coef. & Std. Error & $\mathrm{t}$ & Sig. \\
\hline Constant & 5.237 & 0.774 & 6.764 & 0.000 \\
Level of utilization SMPs & 1.535 & 0.444 & 3.456 & $0.001^{* *}$
\end{tabular}

$\mathrm{F}(1,148)=11.941$, Prob $>F=0.001, R^{2}=0.075$, Adj $R^{2}=0.068$

$* *=$ Significant at $5 \%$ level 
The results in Table 10 showed that the p-value of the model was 0.036 which is statistically significant indicating that the model used was fit to analyze the variables. Utilization of WhatsApp in agriculture was statistically significant $(\mathrm{p}=0.039)$ at a $5 \%$ level of significance. In which, WhatsApp had a positive effect on youth participation in agriculture, increasing youth participation by $26.5 \%$. Therefore, the null hypothesis is rejected hence the alternative is accepted and a conclusion is made that there is a statistically significant effect on the level of utilization of WhatsApp on youth participation in agriculture. Also, the results showed that the utilization of M-Shamba in agriculture was statistically significant $(p=0.026)$ at a $5 \%$ level of significance. M-Shamba had a negative effect on youth participation in agriculture thus decreases the number of agricultural activities by $44.5 \%$. Therefore, the null hypothesis is rejected hence the alternative is accepted and a conclusion is made that there is a statistically significant effect on the level of utilization of M-Shamba on youth participation in agriculture.

Additionally, the level of utilizing Facebook was not statistically significant $(\mathrm{p}=0.816)$ at a $5 \%$ level of significance. Therefore, the null hypothesis was accepted and the conclusion made that there was no statistically significant effect on the level of utilization of Facebook on youth participation in agriculture. Likewise, utilizing of Twitter was not statistically significant $(p=0.652)$ at a
$5 \%$ level of significance. Therefore, the null hypothesis was accepted and the conclusion made that there was no statistically significant effect on the level of utilization of Twitter on youth participation in agriculture.

Moreover, the results revealed the level of utilizing Google search engines was not statistically significant $(\mathrm{p}=0.356)$ at a $5 \%$ level of significance. Therefore, the null hypothesis was accepted and a conclusion was made that there was no statistically significant effect on the level of utilization of Google search engines on youth participation in agriculture. Also, the level of utilizing YouTube was not statistically significant $(\mathrm{p}=0.226)$ at a 5 $\%$ level of significance. Therefore, the null hypothesis was accepted and the conclusion made that there was no statistically significant effect on the level of utilization of YouTube on youth participation in agriculture.

Furthermore, the level of utilizing LinkedIn was not statistically significant $(\mathrm{p}=0.654)$ at a $5 \%$ level of significance. Therefore, the null hypothesis was accepted and the conclusion made that there was no statistically significant effect on the level of utilization of LinkedIn on youth participation in agriculture. Also, the level of utilizing Mkulima Young was not statistically significant $(p=0.680)$ at a $5 \%$ level of significance. Therefore, the null hypothesis was accepted and the conclusion made that there was no statistically significant effect on the level of utilization of Mkulima Young on youth participation in agriculture.

Table 10. Effect of Level of the utilization of social media platforms on youth participation in agriculture.

\begin{tabular}{|c|c|c|c|c|}
\hline Youth Participation in Agriculture & Coef. & $\mathrm{SE}$ & $\mathrm{z}$ & $\mathrm{p}$-value \\
\hline WhatsApp & 0.265 & 0.129 & 2.060 & $0.039 * *$ \\
\hline Facebook & -0.029 & 0.126 & -0.230 & 0.816 \\
\hline Twitter & -0.136 & 0.301 & -0.450 & 0.652 \\
\hline Google Search Engine & 0.119 & 0.129 & 0.920 & 0.356 \\
\hline YouTube & 0.175 & 0.144 & 1.210 & 0.226 \\
\hline Instagram & 0.162 & 0.402 & 0.400 & 0.688 \\
\hline LinkedIn & -0.291 & 0.649 & -0.450 & 0.654 \\
\hline Wikipedia & 0.271 & 0.303 & 0.890 & 0.371 \\
\hline Mkulima Young & 0.096 & 0.233 & 0.410 & 0.680 \\
\hline M-Shamba & -0.445 & 0.199 & -2.230 & $0.026^{* *}$ \\
\hline DigiCow & -0.695 & 0.604 & -1.150 & 0.250 \\
\hline Number of observations & 150 & & & \\
\hline Wald $\operatorname{chi}^{2}(14)$ & 20.720 & & & \\
\hline Prob $>$ chi $^{2}$ & 0.036 & & & \\
\hline Log pseudo-likelihood & 129.062 & & & \\
\hline Pseudo $\mathrm{R}^{2}$ & 0.074 & & & \\
\hline
\end{tabular}

**Statistically significant at $5 \%$ level 


\section{DISCUSSION}

There were more male youths engaged in agricultural activities than females. The work carried out in agriculture can at times be tedious and require great manpower hence males are most likely to engage in the agricultural work than females. According to Muhammad-Lawal et al. (2009) (2009), the gender of an individual can influence the type and quality of work they carry out whereby man are likely to carry out agricultural activities that are labor intensive that female hence the use of social media in agriculture can help improve female youth participation in agriculture since it is not labor intensive. The majority of the respondents were under the age of 25 years which implied that the youth are still interested in agriculture from a younger age, therefore, it is of importance to enhance the teaching of agriculture in secondary schools and provide post-secondary trainings which includes with the use of technology to keep the young farmers attracted to agriculture and promote youth participation in agriculture.

Likewise, there was high participation of youths with secondary education which could be associated with the awareness of more modern technologies and have more information about innovative farming that they might have attained as they get access to more formal. Adesina and Favour (2016) confirm the results by stating that formal education enhances the adoption of modern agricultural technologies by the youth hence promote youth participation in agriculture. A higher number of the respondents were self-employed, this was because the respondents engaged in farming as a full-time job. Okello (2017) confirms the results by indicating that income plays an important role in accessing agricultural information on ICT platforms because the higher the income of the farmer, the more likely to seek different sources of agricultural information. Therefore, the youth farmers can be motivated to participate in agriculture as they obtain information from social media platforms hence it is important for the agricultural information to be readily available on such platforms.

Furthermore, the respondents indicated Facebook, Google search engine, and WhatsApp as the top three highly used social media platforms in agriculture by the youth in Njoro Sub-county. These results conform to the study findings from India by Lathiya et al. (2015)as they indicated that dairy farmers and animal keepers represent a large group of active users of the Facebook social media network. Umunakwe (2018) confirm the high usage of Facebook and WhatsApp in agriculture by indicating that the most dominantly used social media platforms in agriculture are Facebook, WhatsApp, and Twitter with Facebook being the most used, followed by WhatsApp and Twitter being the least of the two in a study carried out in Nigeria. Agricultural extension officers should frequently use Facebook WhatsApp to disseminate agricultural information to the youth farmers. The growing usage of social media to obtain the necessary information by youth is a new and efficient way to engage many youths in agriculture and inspire them to be more productive and innovative as a piece of agricultural information communicate via SMPs can easily reach so many youths within a short time without adding much cost to extension officers or farmers such as traveling. Demonstration of best agricultural practices that are affordable can be easily made through video using social media platforms. An increase of youth participation in agriculture will increase agricultural output in the country which will contribute to food security. Moreover, the unemployment level will be reduced and the incomes of many will raise which will mean an increase in the purchasing power and standard of living.

Additionally, the results of the study carried out by Sokoya et al. (2012) in Nigeria also confirm that Facebook is the most used social media network in agriculture.Paudel and Baral (2018) revealed that Facebook has proved to be a significant tool used by agricultural extension professionals to communicate with farmers in Nepal. Moreover, Barau and Afrad (2017) revealed that Facebook is the most predominately used social media platform in the field of agriculture to obtain agricultural information from agricultural extension professionals in Bangladesh. However, in as much as the youth are predominately using Facebook in agriculture, there are also other platforms that they use such as YouTube.

The respondents used the social media platforms to obtain information crop husbandry practices which includes information on crop diseases, pest's management, cropping systems, and type of crops to plant, and suitable for their environment. This is because most of the respondents are involved in crop production activities which is the main agricultural activity in the area. The respondents are mostly involved in growing maize, wheat, tomatoes, kales, cabbages, carrots, onions 
and green peppers which are the main crops found in the area. Also, the respondents obtained information on markets and use social media to market their produce implying that social media platforms play an important role in agricultural marketing. Cui (2014) confirms that small business's farmers' markets have also taken advantage of Facebook as a marketing channel for their agricultural produce as it is a convenient forum for farmers to come together and market online.

However, the minority of the respondents obtained information about financial services on social media platforms. This was because the respondents did not meet the set criteria for accessing credit from the financers which include the provision of collateral as they just started in the farming business. Njeru, Mano, et al. (2015) conform to the results by stating that to access credit from the banks, the farmer must have an account and provide collateral and also pass through the vigorous vetting processes followed to determine the ability to repay the credit.

However, not all the respondents obtained agricultural information from social media networks. The respondents not using social media associated the nonuse to lack of smartphones, costly internet bundles, and lack of awareness about the use of social media in agriculture. The government should also establish resource centers for the youth to have access to computers and the internet to access agricultural information on social media to promote their participation in agriculture. The more information the youth have access to, there more they can venture into agricultural activities that are of interest to them and that they have information about.

Mkulima Young, DigiCow and M-Shamba are among the least used applications by the youth farmers despite that they were developed in Kenya. This is because they are not commonly known in other parts of the world. Mkulima Young is an online application that helps farmers obtain inputs, sell their products and meet with fellow farmers (Lohento and Ajilore, 2015). DigiCow is an application that is used by dairy farmers to keep records of their milk production, the health of the cow, feeds and sales (Graduate Farmer, 2018) whereas MShamba is an interactive platform that gives farmers agricultural information on production, harvesting, climate, weather and credit and marketing (Kuteesa and Kyotalimye, 2019). This means that the youth farmers might be missing out on very important information that can help improve their agricultural activities issued through these platforms. Therefore, sensitization of the youth on the social media platforms that had low usage such as M-Shamba is very important because these platforms may provide information that is beneficial to the youth that can promote their participation in agriculture. Moreover, there is a serious need for the authorities in charge of M-Shamba and DigiCow to make their work more visible and accessible by creating awareness through other SMPs such as Facebook and WhatsApp which are accessible to many youths. When the government and other stakeholders invest in digital extension services, the information in those platforms will easily reach the majority of the ultimate users and inspire more youths to participate in agricultural activities and its value chain.

Facebook, WhatsApp, and Google search engine were social media platforms that the respondents used very often to access agricultural information as compared to other social media platforms they use. The study carried out in Uganda by Byomire et al. (2016) revealed that the most often used social media platforms by agriculturists were WhatsApp and Facebook which conforms to the results. The respondents can receive information in different forms from WhatsApp, Facebook and Google search engine which led to the high usage of the platforms. Thakur and Chander (2018) indicated that WhatsApp allows information to be delivered in various ways such as audios, texts, pictures and videos which makes it the most preferred by farmers A study carried out by Kuria (2014) in Kenya revealed that, the respondents in the study area social media platforms' use various from weekly to monthly basis depending on the popularity of the platforms. Therefore, the popularity of the platforms amongst the farmers explains the observed variation of utilization of the social media platforms. If a platform is popular, there is more interaction taking place and more information accessed and utilized as compared to the less popular platforms.

It is very important for awareness on the various social media platforms available to be created so that farmers can be able to utilize information on the platforms that were not common to them. According to Kipkurgat et al. (2016) farmers use a variety of sources to obtain agricultural information such as the internet, agricultural extension officers and social media, however, social media has been highly adopted by 
farmers in Kesses district, Kenya as compared to other sources.

The study findings by Babu et al. (2012) in India revealed that farmers source agricultural information from newspapers, progressive farmers, television, family members or relatives, state government agricultural extension staff, and private dealers. However, in the same study, Babu et al. (2012) indicated that mobile phones may be a useful and timely method of delivering knowledge and agricultural information to farmers, which means since social media uses mobile device services can be relied on as a medium of disseminating agricultural information. This implies that digital agricultural extension is the new or the next approach to extension services that efficient and effective and cannot be ignored or avoided otherwise traditional approach to agriculture extension will be irrelevant and lack clients to serve.

Watts (2018) support the study findings by stating that agriculturist should explore other methods of communication such as the traditional face to face approach alone has proven not to be efficient though some farmers are still lagging on the latest technology such as smartphones and Internet. Therefore, with the inefficiency of face-to-face agricultural information dissemination, social media will come in handy to disseminate information to the farmers. Varner (2018) stated that the farmers who are not using social media in agriculture are missing out on great opportunities to interact, educate the public and promote their farms and their products. This might be because some youth are slow in adopting new technologies which might contribute to the slow shift of the traditional approach to a digital approach which is effective and more efficient. This delay might contribute to poor agricultural results and thus sensitization and facilitation might help them not to lag. Also, training needs to be done on the use of social media in agriculture so that farmers do not miss out on opportunities to grow.

There was a statistically significant effect of the level of utilization of social media platforms on youth participation in agriculture. The respondents who are using WhatsApp very often in agriculture had the likelihood of undertaking a higher number of agricultural activities. This is because WhatsApp allows the respondents to engage directly with the professionals through direct messages, video calls, voice calls, share pictures, and videos, and also engage with other farmers and professionals in the groups. The study by Naruka et al. (2017) in India revealed that WhatsApp groups are connecting farmers with their customers in the virtual market and they also create a network of resources and support for farmers who need it. Sharing of inspirational and successful agricultural stories via this platform might inspire even those who are not in agriculture to get into agricultural activities.

Likewise, there was a statistically significant effect on the level of utilization of M-Shamba on youth participation in agriculture whereby the respondents who used M-Shamba undertook a low number of agricultural activities. This is mainly because the platform does not provide a variety of agricultural information that can meet the needs of the farmers entirely. According to Calvince Okello, the founder of MShamba, the main challenge they faced is that they have not been able to expand to meet the expectations of their potential clients (Vutagwa, 2017). Therefore, if MShamba is not able to meet all the needs of the youth farmers it means the farmers are not able to get more information on different agricultural activities, hence their agricultural activities did not increase. Sensitizing the youth on the use of M-Shamba is important so they do not miss the important information portrayed on using the platform that may help improve their participation in agriculture.

Moreover, there was no statistically significant effect on the level of utilization on Facebook on youth participation in agriculture whereby the respondents who used Facebook did not show any significant change in the number of agricultural activities they undertook. This is because Facebook is mostly used for socializing and sharing personal information and most of the information communicated on Facebook is not by professional extension officers which did not motivate the youth farmers to increase their participation in agriculture. In support of the results, (Thakur and Chander, 2018) revealed that the social characteristic of Facebook proved to be a hindrance among respondents in seeking and sharing agricultural information in India. The youth farmers tend to focus more on the social interactions on Facebook rather than seeking agricultural information to help improve their agricultural productivity and motivate themselves to engage more in agriculture. Creating more professional agricultural groups on Facebook can improve the professionalism of the agricultural content shared and 
professional interactions with agricultural experts that may promote youth participation in agriculture.

Likewise, there was no statistically significant effect on the level of utilization of Twitter on youth participation in agriculture whereby the respondents who used Twitter did not show any significant change in the number of agricultural activities they undertook. Twitter is a social media platform that allows farmers to publish messages of up to 280 characters to market their agricultural produce and interact with consumers (Zipper, 2018). The 280-character limit of Twitter seems to limit the dissemination of information in which much explanation is needed on certain agricultural concepts. This left the farmers not being able to fully utilize the agricultural information shared via Twitter to improve their productivity and improve their participation in agriculture.

Due to the character limit on Twitter, the agricultural information was promoted using hashtags, which also did not promote youth participation in agriculture as the information was still not being fully utilized by the youth farmers. According to the Animal Agriculture Alliance (2020), a hashtag on Twitter is used to denote a larger conversation of what people are talking about based on the subjects, words and themes. In support of the results, the study carried by Besancon (2017) in the United States of America revealed that hashtags were being "hijacked" and ended up not disseminating the needed agricultural information citing an example of the hashtag \#farm365 which was intended to promote traditional agriculture, was "hijacked" and used to promote veganism and animal rights. This "hijacking" of hashtags made it difficult for the relevant agricultural information to reach the targeted youth farmers, hence they are not able to gather much-needed information to engage in agriculture.

Furthermore, there was no statistically significant effect on the level of utilization of Google search engines in agriculture on youth participation in agriculture. This implied that using the respondents using the Google search engine did not show any statistically significant change in the number of agricultural activities they undertook. This is because Google search engine gives out thousands of results by just typing a keyword, of which some of the results are not relevant to the farmers. A study carried out by (Agboola, 2017) in Nigeria revealed that using the Google search engine can give about 499,000,000 results. With Google search engine showing this large number of results, it becomes difficult for the youth farmers to filter through the most relevant information sought hence they are not able to use the information sought to help improve their participation in agriculture. If the youth farmed do not get the relevant information they need, they are not able to engage more in agriculture as information brings change.

Also, there was no statistically significant effect on the level of utilization of YouTube in agriculture on youth participation in agriculture. This implied that using the respondents using the Google search engine did not show any statistically significant change in the number of agricultural activities they undertook. The majority of young farmers and ranchers use YouTube to market their products, raise awareness about specific growing practices, share learning and experiences with their fellow farmers (Nittle, 2020). This makes lots of videos to be availed on the platform which are mostly not made by experts. This gives way to unprofessional and misleading agricultural information that does not help youth farmer to improve their agricultural productivity and hence increase their participation in agriculture. Also, watching YouTube videos is costly in terms of buying internet bundles, which makes the videos not to be accessible to the majority of the youth farmers to utilize the agricultural information to improve their participation in agriculture. Making YouTube videos on other social media platforms such as WhatsApp will improve their accessibility to the youth farmers and help promote their participation in agriculture.

Moreover, there was no statistically significant effect on the level of utilization of LinkedIn in agriculture on youth participation in agriculture. This implied that using LinkedIn did no increase the number of agricultural activities the respondents undertook. This is because LinkedIn is mostly used by professionals, the interactions are only on a professional level. According to Simonson (2013), LinkedIn is the number one choice for professional communication where the professional, well-informed discussion takes place and does not give room for personal discussions. Young farmers tend to be inspired by personal stories of success that motivates them to engage more in agriculture. Therefore, not being able to interact at such a level on LinkedIn did not help in promoting youth participation in agriculture as the youth farmers who are not able to interact in a highly professional manner are left out of the opportunity to 
utilize the agricultural information disseminated through the platform. Youths must first develop trust and passion for them to engage in a certain activity. When a platform lacks interaction, it is difficult for youths to develop trust and have good confidence in the success of the activity.

Additionally, there was no statistically significant effect on the level of utilization of Mkulima Young on youth participation in agriculture. This is mainly because the platform is used mainly as the marketing center whereby the youth using this platform mainly used it to market their produce hence did not meet some of the needs of the farmers. This platform helps the youth farmers get access to the much-needed market but does not cater for the production needs of the farmers that will help them engage in more productive activities hence improve their participation in agriculture as information the platform encourages them to specialize on few activities. However, the platform can influence and inspire youths to engage in more agricultural activities that are profitable and relevant to their environment which will increase food production, incomes and lower unemployment levels (Lohento and Ajilore, 2015).

\section{CONCLUSIONS AND RECOMMENDATIONS}

The majority of the respondents used Facebook, WhatsApp, Google Search engine, and YouTube which are the commonly known social media platforms in the field of agriculture. The respondents' level of utilization of social media platforms varied across the various platforms from no using the platforms at all to very often use of the social media platforms. The level of utilization of social media platforms affected youth participation in agriculture such that using WhatsApp more often showed an increase in the number of agricultural activities the respondents undertook. Shamba platform had the lowest usage by the respondents hence the negative effect on youth participation in agriculture. The study recommended that government and other potential stakeholders should facilitate the structural shift in facilitating access to extension services by investing in Digital Extension Services to promote the majority of youth to participate in agriculture as the country's energetic population which is highly affected by unemployment. More youth participation would significantly reduce the unemployment level in the country, increase their income and standard of living, reduce the dependency ratio of the country, and contribute to food security as well as encouraging the development of many small business enterprises and export businesses which will increase the country's earnings and revenue. The government should establish resource centers for farmers to access the internet and computers to use social media to obtain agricultural information. The agricultural extension department in the Ministry of Agriculture, Livestock and fisheries should hold campaigns and training to create awareness and sensitize the youth on the use of social media platforms available to obtain agricultural information. Stakeholders such as network service providers should be brought on bought and help come up with subsidized bundle packages to as with costs of data bundles when farmers access agricultural information.

\section{ACKNOWLEDGMENTS}

Thank you to the respondents in Njoro Sub-county for helping me by giving out the most vital information for this work. Special thank you to agricultural extension officers for enabling me to carry out this research by coordinating meetings with the respondents. Special appreciation to the African Centre of Excellence in Sustainable Agriculture and Agribusiness Management (CESAAM) for funding this research.

\section{REFERENCES}

Adesina, T. K. and E. Favour. 2016. Determinants of Participation in Youth-in-Agriculture Programme in Ondo State, Nigeria. Journal of Agricultural Extension, 20: 104.

Agboola, J. O. 2017. Google It: Re-branding agriculture. .

Akashraj, D. and C. Pushpa. 2014. Role of social media on development. Merit Research Journal of Education and Review, 2: 15-18.

Babu, S. C., C. J. Glendenning, K. A. Okyere and S. K. Govindarajan. 2012. Farmers' information needs and search behaviors: Case study in Tamil Nadu, India.

Balkrishna, B. B. and A. A. Deshmukh. 2017. A study on role of social media in agriculture marketing and its scope. Global Journal of Management and Business Research.

Barau, A. A. and M. S. I. Afrad. 2017. An overview of social media use in agricultural extension service delivery. Journal of Agricultural Informatics, 8.

Byomire, G., F. Namisango and M. M. Kafuko. 2016. Use 
of Social Media to strengthen Service Delivery for Urban Agriculture in Uganda 2016 IST-Africa Week Conference. IEEE.

Cline, M. 2011. Expansion of social media in agriculture: A user profile of Twitter's@ AgChat,@ FollowFarmer and@ TruffleMedia followers, Oklahoma State University.

Cui, Y. 2014. Examining Farmers Markets' Usage of Social Media: An Investigation of a Farmers Market Facebook Page. Journal of Agriculture, Food Systems, and Community Development: 117.

Heide-Ottosen, S. 2014. The ageing of rural populations: evidence on older farmers in low and middleincome countries. HelpAge International: London, UK.

Kenya National Bureau of Statistics. 2019a. 2019 Kenya population and housing census volume IV: Distribution of population by socio-economic characteristics.

- — . 2019b. 2019 Kenya population and housing census, volume II: distribution of the population by age and sex.

Kimaro, P. J. and N. N. Towo. 2015. Determinants of rural youth's participation in agricultural activities: the case of Kahe East ward in Moshi rural district, Tanzania. International Journal of Economics, Commerce and Management, 3: 33.

Kipkurgat, T., M. Onyiego and S. Chemwaina. 2016. Impact of social media on agricultural extension in Kenya: a case of Kesses District. International Journal of Agricultural Extension and Rural Development Studies, 3: 30-36.

Kotrlik, J. and C. Higgins. 2001. Organizational research: Determining appropriate sample size in survey research appropriate sample size in survey research. Information technology, learning, and performance journal, 19: 43.

Kuria, C. W. 2014. Use of social media as a source of agricultural information by small holder farmers; a case study of lower Kabete, Kiambu county, University of Nairobi.

Lathiya, A., A. Rathod and K. Choudhary. 2015. Role of social media in agriculture. INTERNATIONAL JOURNAL OF COMMERCE AND BUSINESS MANAGEMENT, 8: 268-73.

Lohento, K. and O. Ajilore. 2015. ICT and Youth in Agriculture. Africa Agriculture Status Report: 118-
42.

Ministry of Agriculture Livestock and Fisheries. 2017. Kenya Youth Agribusiness Strategy 2017-2021: Positioning the youth at the forefront of agricultural growth and transformation.

Muhammad-Lawal, A., O. Omotesho and A. Falola. 2009. Technical efficiency of youth participation in agriculture: A case study of the youth-inagriculture programme in Ondo State, south western Nigeria.

Naruka, P., S. Verma, S. Sarangdevot, C. Pachauri, S. Kerketta and J. Singh. 2017. A Study on Role of WhatsApp in Agriculture Value Chains. Asian Journal of Agricultural Extension, Economics \& Sociology, 20: 1-11.

Nittle, N. 2020. Can YouTube give farmers a financial boost?

Njeru, L., B. Gichimu, M. Lopokoiyit and J. Mwangi. 2015. Influence of Kenyan Youth's Perception towards Agriculture and Necessary Interventions; a Review. Asian Journal of Agricultural Extension, Economics \& Sociology, 5: 40-45.

Njeru, L. K. and J. G. Mwangi. 2015. Influence of youth access to farm products markets on their participation in agriculture in Kajiado North Subcounty.

Njeru, T. N., Y. Mano and K. Otsuka. 2015. Role of Access to Credit in Rice Production in Sub-Saharan Africa: The Case of Mwea Irrigation Scheme in Kenya. Journal of African Economies, 25: 300-21.

Okello, D. 0. 2017. Effect of ICT use on performance of Agri-enterprises. A case of smallholder pineapple farmers in Kiambu County, Kenya, Egerton University.

Olwande, J. and M. K. Mathenge. 2011. Market participation among poor rural households in Kenya.

Paudel, R. and P. Baral. 2018. Social media in agricultural extension. Agricultural Extension Journal, 2: 6974.

Poushter, J., C. Bishop and H. Chwe. 2018. Social media use continues to rise in developing countries but plateaus across developed ones. Pew Research Center, 22: 2-19.

Salkind, N. 2010. Encyclopedia of Research Design SAGE Publications, Inc.

Sokoya, A. A., F. N. Onifade and A. O. Alabi. 2012. Establishing connections and networking: the role 
of social media in agricultural research in Nigeria World Library and Information Congress: 78th IFLA General Conference and Assembly.

Starasts, A. 2015. 'Unearthing farmers' information seeking contexts and challenges in digital, local and industry environments'. Library \& Information Science Research, 37: 156-63.

Thakur, D. and M. Chander. 2018. Social Media in Agricultural Extension: Benefits and Challenges under Indian Context. Asian Journal of Agricultural Extension, Economics \& Sociology, 27: 1-8.

Umunakwe, P. C., Madukwe, M.C., Ozor, N., Nnadi, F. N. 2018. Use of social media tools among agricultural students in tertiary institutions in Nigeria: An Insight from the Federal University of Technology, Owerri, Imo State, Nigeria. Middle East Journal of Agriculture Research, 7: 373-82.

Varner, J. 2018. Agriculture and social media. Extension Center for Technology Outreach: Information
Sheet 1946. . Mississippi State University Extension Service.

Vutagwa, C. 2017. Meet Calvince Okello, founder of MShamba. Retrieved September, 17.

Wahiu, R., K. Lohento and F. Koutchade. 2020. ICT uses by rural youth in Kenya: Perspectives from the Vijabiz project.

Wangui, J. C., B. O. Bebe, J. O. Ondiek and S. O. Oseni. 2018. Application of the climate analogue concept in assessing the probable physiological and haematological responses of Friesian cattle to changing and variable climate in the Kenyan Highlands. South African Journal of Animal Science, 48: 572.

Watts, B. 2018. The influence of social media in agriculture. Challenge Advisory.

Zipper, S. C. 2018. Agricultural Research Using Social Media Data. Agronomy Journal, 110: 349-58.

Publisher's note: EScience Press remains neutral with regard to jurisdictional claims in published maps and institutional affiliations.

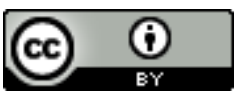

Open Access This article is licensed under a Creative Commons Attribution 4.0 International License, which permits use, sharing, adaptation, distribution and reproduction in any medium or format, as long as you give appropriate credit to the original author(s) and the source, provide a link to the Creative Commons license and indicate if changes were made. The images or other third-party material in this article are included in the article's Creative Commons license, unless indicated otherwise in a credit line to the material. If material is not included in the article's Creative Commons license and your intended use is not permitted by statutory regulation or exceeds the permitted use, you will need to obtain permission directly from the copyright holder. To view a copy of this license, visit http://creativecommons.org/licenses/by/4.0/. 